\title{
Authentication approach using enzyme-linked immunosorbent assay for detection of porcine substances
}

\begin{abstract}
Food manufacturers across the world commonly add animal substances in their food products. Some food products may contain porcine substances including pork, gelatine, blood and pepsin. These substances significantly affect the texture, colour or taste of the end products. Aside from enhancing sensory qualities, additional ingredients also contribute to preservation, bulk and nutrition. However, the inclusion of porcine substances might not be suitable among certain communities. One primary concern is fraud labelling which includes hiding the addition of porcine substances in food. Therefore, analytical techniques such as enzyme-linked immunosorbent assay (ELISA) have been developed to detect the porcine proteins in food. The ELISA delivers specificity and sensitivity in detecting the targeted animal species in food. This review provides an overview of the ELISA technique which has been developed for potential detection of porcine substances in laboratory-prepared food samples and commercial food products.
\end{abstract}

Keyword: ELISA; Porcine substances; Food authentication; Food products 